OPEN ACCESS

Edited by:

Junji Xing,

Houston Methodist Research Institute, United States

Reviewed by:

Marion Russier

Max Planck Institute of Biochemistry,

Germany

Blanca Callejas,

University of Calgary, Canada

*Correspondence:

Sameh Basta

bastas@queensu.ca

Specialty section:

This article was submitted to

Virology,

a section of the journal

Frontiers in Microbiology

Received: 28 October 2021 Accepted: 06 December 2021

Published: 11 January 2022

Citation:

Banete A, Barilo J, Whittaker R and Basta S (2022) The Activated Macrophage - A Tough Fortress for Virus Invasion: How Viruses Strike Back. Front. Microbiol. 12:803427. doi: 10.3389/fmicb.2021.803427

\section{The Activated Macrophage - A Tough Fortress for Virus Invasion: How Viruses Strike Back}

\author{
Andra Banete ${ }^{1,2}$, Julia Barilo', Reese Whittaker ${ }^{1}$ and Sameh Basta ${ }^{1 *}$ \\ ${ }^{1}$ Department of Biomedical and Molecular Sciences, Queen's University, Kingston, ON, Canada, ${ }^{2}$ Department of Biological \\ Sciences, Sunnybrook Research Institute, University of Toronto, Toronto, ON, Canada
}

Macrophages $(\mathrm{M} \varphi)$ are innate immune cells with a variety of functional phenotypes depending on the cytokine microenvironment they reside in. $M \varphi$ exhibit distinct activation patterns that are found within a wide array of activation states ranging from the originally discovered classical pro-inflammatory (M1) to the anti-inflammatory (M2) with their multi-facades. M1 cells are induced by IFN $\gamma+$ LPS, while M2 are further subdivided into M2a (IL-4), M2b (Immune Complex) and M2c (IL-10) based on their inducing stimuli. Not surprisingly, $\mathrm{M} \varphi$ activation influences the outcome of viral infections as they produce cytokines that in turn activate cells of the adaptive immune system. Generally, activated M1 cells tend to restrict viral replication, however, influenza and HIV exploit inflammation to support their replication. Moreover, M2a polarization inhibits HIV replication at the post-integration level, while HCMV encoded hrlL-10 suppresses inflammatory reactions by facilitating M2c formation. Additionally, viruses such as LCMV and Lassa Virus directly suppress $M \varphi$ activation leading to viral chronicity. Here we review how $M \varphi$ activation affects viral infection and the strategies by which viruses manipulate $M \varphi$ polarization to benefit their own fitness. An understanding of these mechanisms is important for the development of novel immunotherapies that can sway $M \varphi$ phenotype to inhibit viral replication.

Keywords: cytokines, polarized macrophages, interleukin-4, interferon-gamma, virus

\section{ACTIVATED MACROPHAGES: THE FOE TO VIRAL INFECTIONS}

Macrophages $(\mathrm{M} \varphi)$ recognize viruses, and bridge innate and adaptive immunity to assist in T cell priming (Naito et al., 1996; Takahashi et al., 1996; Iwasaki and Medzhitov, 2010; Trus et al., 2020; Petrina et al., 2021). M $\varphi$ polarization (Murray et al., 2014; Yunna et al., 2020), occurs in response to changing environmental stimuli where activated $\mathrm{M} \varphi$ can become (M1) associated with Th1 cytokines response, or (M2) associated with Th2 cytokines (Nathan et al., 1983; Stein et al., 1992; Gordon and Taylor, 2005; Yunna et al., 2020). The pro-inflammatory M1 phenotype is induced by lipopolysaccharide (LPS) in the presence of interferon-gamma (IFN $\gamma$ ) (Nathan et al., 1983; Nathan and Hibbs, 1991; Tugal et al., 2013). In contrast, M2 M $\varphi$ function as anti-inflammatory cells and promote tissue repair (Stein et al., 1992; Martinez et al., 2006; Tugal et al., 2013). The M2 designation has been further subdivided into (M2a, b, c, and d) based on the cytokines that induces them and their gene expression profiles (Mantovani et al., 2004). For example, M2a M $\varphi$, involved in parasitic infections (Sica and Mantovani, 2012), can be derived from either bone marrow or 
spleen tissues by short or long-term incubation with IL-4 (Mulder et al., 2017; Banete et al., 2021). Genetic approaches have been used to investigate $\mathrm{M} \varphi$ activation (Biswas and Mantovani, 2010; Smale, 2010; Lawrence and Natoli, 2011), but little is known about dysregulated $\mathrm{M} \varphi$ functions during viral infection (Beadling and Slifka, 2004; Trivedi et al., 2018).

In various infectious diseases, activated $\mathrm{M} \varphi$ produce cytokines such as IL-6, IL-12 and IL-23 to regulate immunity against viral invasion (Arango Duque and Descoteaux, 2014; Ruytinx et al., 2018). IL-12 and IL-23 are induced by diverse $\mathrm{M} \varphi$ populations after Toll-like receptor (TLR) stimulation by viral pathogenassociated molecular patterns (PAMPs) (Gee et al., 2009; Mehta et al., 2015; Petes et al., 2017; Che Mat et al., 2018; Alothaimeen et al., 2021; Banete et al., 2021).

When $\mathrm{M} \varphi$ encounter viruses or viral PAMPs, they begin producing type I IFNs, which are needed to aid with NK and eventually $\mathrm{T}$ cell activation (Kadowaki and Liu, 2002; Keppler et al., 2012). This IFN rapid response starts with the production of IFN- $\beta$ followed by IFN- $\alpha$, causing the phosphorylation of interferon regulatory factor 7 (IRF7), which is needed to enhance the antiviral response (Sun et al., 2013). IRFs can also be activated via the endoplasmic reticulum (ER) adaptor protein stimulator of interferon genes (STING), which detects cytoplasmic DNA from viral infection, resulting in type I IFN induction that interferes with virus replication (Banete et al., 2018). Several viruses have been shown to interfere with this STING-induced type I IFN response (Banete et al., 2018). For example, Dengue virus (DENV) expresses a protease (NS2B3) that cleaves STING causing the reduction of induced type I IFN after infection with DENV (Aguirre et al., 2012).

Other viruses, such as Herpes simplex virus (HSV), have been shown to interfere with type I IFN production in human $\mathrm{M} \varphi$ after infection by expressing a viral inhibitory protein that interferes with the STING signalosome activation of IRF (Christensen et al., 2016). There is evidence that the TRIM family of proteins are critical in the activation of STING. Recent reports show that TRIM29 is expressed in alveolar $\mathrm{M} \varphi$, where they regulate their activation state, acting as a negative regulator of antiviral immune responses (Xing et al., 2017, 2018; Li et al., 2018). TRIM29 was shown to be up-regulated by viral RNA and DNA, with EBV suppressing innate immune responses by targeting STING through the TRIM29 signaling pathway, indicating a mechanism of persistence for DNA viruses. Whether viruses can regulate $\mathrm{M} \varphi$ polarization through TRIM29 remains to be determined. Type II IFN (IFN- $\gamma)$ can directly inhibit Murine Norovirus replication by reducing the levels of both structural and nonstructural viral proteins expression in infected cells (Changotra et al., 2009). Additionally, the ability of IFN- $\gamma$ to induce nitric oxide synthase (iNOS) to aid in how $\mathrm{M} \varphi$ respond to viruses to inhibit Coxsackievirus viral replication (Jarasch et al., 2005). Viruses have developed mechanisms to evade this activation pathway; for example Epstein-Barr virus (EBV) encodes several proteins that inhibit IFN- $\gamma$ as well as type I IFNs by targeting the activation of the JAK-STAT signaling pathways (Taylor et al., 2015; Jangra et al., 2021).

In addition to IFNs, other cytokines secreted by activated $\mathrm{M} \varphi$, such as IL-1 $\beta$, and IL-6, can also contribute to antiviral activities due to their ability to activate MAPK/ERK signaling pathways (Lucin et al., 1994; Ichikawa et al., 2002; O’Neill, 2008; Tanaka et al., 2014; Mariani et al., 2019). Thus, activated $\mathrm{M} \varphi$ can help mediate viral restriction by producing a variety of cytokines which could also be influenced by their polarization states.

Studies on HIV-1 have characterized some of the antiviral responses observed in $\mathrm{M} \varphi$ (Cassol et al., 2009; Li et al., 2009). In $\mathrm{HIV}-1, \mathrm{M} 2 \mathrm{a} \mathrm{M} \varphi$ inhibit virus replication to a certain degree without impairing viral entry or reverse transcriptase activities, suggesting that inhibition occurs in the later events of the viral cycle, while M1 cells downregulate CD4 expression to prevent HIV-1 entry into cells (Cassol et al., 2009). The mechanism behind the impaired virus replication in $\mathrm{M} 2 \mathrm{a}$ cells has not been fully elucidated in the above model. Though, in other viral infections, HSV-1 replication was observed to be significantly higher in M2 than M1 cells in vitro, but in vivo, M2 cells were better at restricting viral replication (Lee and Ghiasi, 2017). Thus, viral inhibition by M2a cells could be limited to certain viral models. Indeed, more studies are needed to carefully delineate the mechanism of antiviral responses in activated $M \varphi$, because certain virus infections could benefit from the $\mathrm{M} \varphi$ polarization status.

\section{HOW VIRUSES COUNTER M $\varphi$ ACTIVATION}

$\mathrm{M} \varphi$ are early targets for viral infection, and their activation by infection plays a crucial role in regulating innate and adaptive immunity. Many studies show that pathogenic Arenaviruses such as LASV and Junin virus (JUNV) are highly immunosuppressive, in contrast with their non-pathogenic counterparts Mopeia virus (MOPV) and Tacaribe virus (TCRV). Infection does not activate human $\mathrm{M} \varphi$ upon infection, and patients who succumb to hemorrhagic disease lack a significant upregulation of pro-inflammatory cytokines in their sera (Baize et al., 2004). As well, the pathogenic LCMV has also been shown to inhibit $\mathrm{M} \varphi$ activation, in contrast to Pichinde arenavirus, which does not cause disease in humans (Xing et al., 2015a). LCMV infection of human monocyte-derived $\mathrm{M} \varphi$ does not upregulate cytokine production and the co-stimulatory molecules CD80 and CD86, leading to the inhibition of $\mathrm{M} \varphi$ activation (Xing et al., 2015a).

Furthermore, infection with human cytomegalovirus (HCMV) is associated with immunological dysfunction. Studies show that HCMV encodes different gene products that can modulate immune functions to enhance viral pathogenesis. UL111A encodes homologs of the anti-inflammatory cytokine human IL-10 during both the acute and latent stages of infection (Kotenko et al., 2000; Jenkins et al., 2004). M $\varphi$ polarization is skewed toward a deactivated M2c phenotype, with downregulated pro-inflammatory cytokine production, and inhibition of MHC I and II expression (Avdic et al., 2013). As well, M2c polarization by HCMV viral IL-10 reduces their ability to stimulate CD4 $\mathrm{T}$ cell activation and proliferation (Avdic et al., 2013). Thus, it is crucial to further understand how viruses can manipulate the activation state of $\mathrm{M} \varphi$ to benefit 
their own replication, as it may help in the development of immunotherapies.

As highlighted above, M1 M $\varphi$ are associated with the production of inflammatory cytokines (Sica et al., 2015), and are prominent in the initial stages of the antiviral immune response (Gracia-Hernandez et al., 2020). Thus, $\mathrm{M} \varphi$ represent key targets for viruses to infect (Sang et al., 2015). This has been observed in viral infections such as with $\mathrm{HIV}$, where $\mathrm{M} \varphi$ act as a reservoir for HIV due to their long half-life. African Swine Fever Virus (ASFV) is another virus that infects many types of $\mathrm{M} \varphi$ (Basta et al., 1999, 2001; McCullough et al., 1999). In vivo, increased numbers of $\mathrm{M} \varphi$ after ASFV infections were observed and they tend play a role in ASF viral pathogenesis by contributing to increased levels of proinflammatory cytokines, typically associated with M1 cells that can cause severe pathology (Gomez-Villamandos et al., 2013; Paulina Achita, 2015).

The role IL-6 plays during viral clearance has been shown to favor viral infections in mice infected with Theiler's murine encephalomyelitis virus (Hou et al., 2014). In this study, excessive levels of the IL-6 cytokine were observed due to viral infection. This causes an increased number of inflammatory IL17-producing helper T cells. The combined effects of IL-6 and IL-17 synergistically allow for viral persistence because virusinfected cells were protected from undergoing apoptosis (Hou et al., 2014). Thus, high levels of IL- 6 benefit the virus in this infection model.

The excessive polarization of $\mathrm{M} 1$ and $\mathrm{M} 2 \mathrm{M} \varphi$ can be correlated with viral infection and its related complications, such as sepsis and acute respiratory distress syndrome (ARDS) (Zhang et al., 2019). M1-polarized cells can be problematic in certain viral infections, as they recruit other cell populations to the inflammation site, which creates a favorable environment for virus infection of immune cells (Herbein and Varin, 2010; Nikitina et al., 2018). An example of M1 M $\varphi$ promoting viral dissemination is in the acute phase of HIV infection. This phase is characterized by a predominance of $\mathrm{M} 1 \mathrm{M} \varphi$ expressing the proinflammatory cytokines TNF- $\alpha$, IL-1 $\beta$, IL-6 and IL-18 (Burdo et al., 2015; Nikitina et al., 2018). This seems to aid in HIV spread, since inflammation promotes the recruitment of more monocytes and T-cells to the site, which allows HIV to infect these cells and establish infection in the host.

In SARS-CoV-2 severe infections, monocytes are recruited to the lungs where they differentiate into $\mathrm{M} \varphi$ that tend to upregulate pro-inflammatory genes needed for T-cells activation (GraciaHernandez et al., 2020; Zheng et al., 2021). The continuous recruitment of inflammatory monocytes to lung tissues can be harmful to the host as it distorts pulmonary $\mathrm{M} \varphi$ to persist in the active M1 state (Morales-Nebreda et al., 2015). This bias toward M1 M $\varphi$ during viral infection can cause undesirable pathological inflammatory response leading to ARDS (Brufsky, 2020). In ARDS, high levels of inflammatory cytokines especially IL-6 are problematic (Zheng et al., 2021). In this scenario, high levels of pro-inflammatory cytokines enhance viral persistence, multiorgan failure, vascular permeability and possibly death (Gracia-Hernandez et al., 2020).

It has recently been shown that infection of $\mathrm{M} \varphi$ by SARS-CoV2 triggers M2-associated gene expression in vivo. In addition, infection of polarized $\mathrm{M} 1$ and $\mathrm{M} 2 \mathrm{M} \varphi$ significantly increases the release of both pro- and anti-inflammatory cytokines after 24 and $48 \mathrm{~h}$. Interestingly, although all $\mathrm{M} \varphi$ subtypes were susceptible to SARS-CoV-2 infection, viral load was significantly lower in M2 compared to M0 (Boumaza et al., 2021). The higher permissivity of M0 and M1 macrophages to SARS-CoV2 infection may be why conditions associated with excessive M1 polarization, such as obesity and diabetes, are comorbidities of COVID-19.

Another example where the virus makes use of $M \varphi$ is seen in Human Cytomegalovirus (HCMV) where the virus is able to establish a low-level productive infection in both types of $\mathrm{M} \varphi$ (M1 and M2) for a total of 21 days in vitro culture (Bayer et al., 2013). Both types of $M \varphi$ display features of activation with upregulation of inflammatory cytokines such as IL-6 and TNF- $\alpha$ (Bayer et al., 2013). It has been shown that HCMV can regulate the polarization of infected $\mathrm{M} \varphi$ to create a favorable environment for the virus to disseminate (Nikitina et al., 2018). These examples remind us of the importance of studying $\mathrm{M} \varphi$ responses in different models of viral infections.

\section{VIRAL TRICKS TO AVOID PATHOGEN RECOGNITION RECEPTORS ACTIVATION}

Viruses PAMPs are recognized by pathogen recognition receptors (PRRs) expressed by $\mathrm{M} \varphi$ (Kawai and Akira, 2009). PRRs include Toll-like receptors (TLRs), the retinoic-acidinducible gene I (RIG-I)-like receptors (RLRs), melanoma differentiation-associated gene 5 (MDA5), and NOD-like receptors (NLRs) (Takeuchi and Akira, 2010). Endosomal TLRs recognize viral nucleic acids. Upon encountering infections, these receptors help in the initiation of immune responses, inducing the influx of inflammatory cells to the site of infection (Biswas and Mantovani, 2010).

In response to PRRs stimulation (Figure 1), IRFs and NF- $\kappa \mathrm{B}$ are activated to induce IFN production and pro-inflammatory cytokines. IRF1, 3, and 7 have been implicated as positive regulators of type I IFN transcription. IRF3 and 7 are essential for the cytosolic pathway induction of type I IFN, whereas IRF1 is non-essential. IFN signaling then initiates a positive feedback loop, acting in autocrine and paracrine manners to induce interferon-stimulated genes (ISGs). Two essential ISGs involved in RNA virus infections are RIG-I and MDA5, recognizing cytoplasmic ssRNA and dsRNA, respectively (Reikine et al., 2014). Upon interaction with their ligands, RIG-I and MDA5 oligomerize to form filaments, interacting with their adaptor protein MAVS to induce filament formation and signaling. Activated MAVS form large, prion-like aggregates (Hou et al., 2011). It has been shown recently that membrane-bound organelles are platforms for immune signaling events (Vazquez and Horner, 2015). In addition to the mitochondria, MAVS has also been found on peroxisomes, where it can induce a unique signaling pathway that specifically triggers IFN $\lambda$ expression but not IFN $\beta$ in response to certain viral infections (Dixit et al., 2010; Odendall et al., 2014; Bender et al., 2015). 


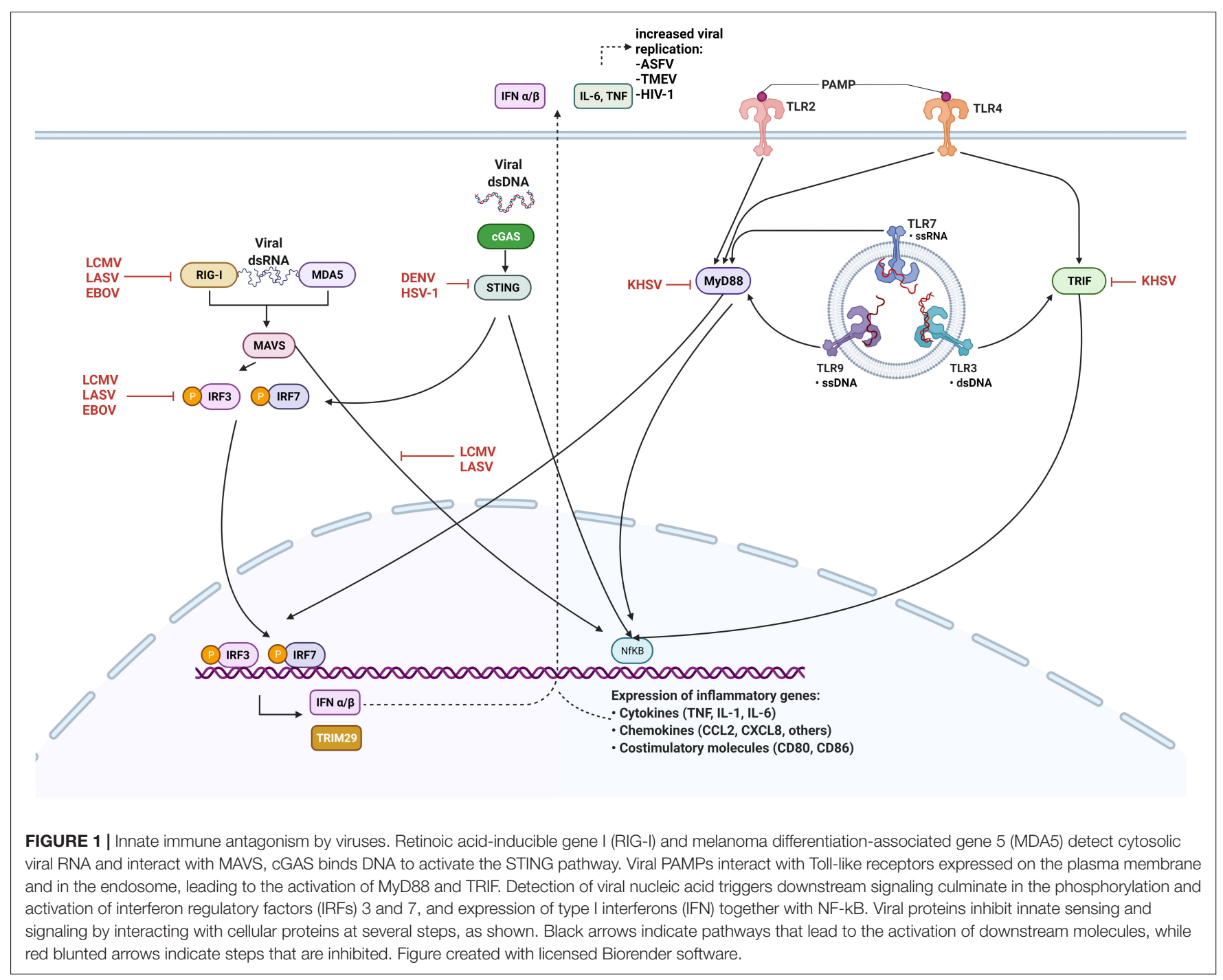

Another sensor of RNA virus infection in $\mathrm{M} \varphi$ is poly ADPribose polymerase 9 (PARP9) (Xing et al., 2021). Interestingly, PARP9 is required to control RNA virus infection in STAT1dependent signal transduction, enhancing IFN-regulated host responses (Zhang et al., 2015). While PARP9 increases M1associated gene expression (Iwata et al., 2016), PARP14 has been shown to enhance IL-4-dependent gene expression (Mehrotra et al., 2011). All members of the Coronaviridae family encode a macrodomain that reverse ADP-ribosylation by PARP proteins (Grunewald et al., 2019), and recently the SARS-CoV-2 Nsp macrodomain has been shown to impair IFN signaling and induction of IFN-responsive genes (Russo et al., 2021).

Moreover, TLR signaling pathway molecules are targets for viral inhibition. Arenaviruses are able to inhibit a TLR2 response through the suppression of NF- $\mathrm{kB}$ activation by the viral NP (Rodrigo et al., 2012). The Arenavirus NP plays several roles in the suppression of immune responses (Martinez-Sobrido et al., 2007). It is able to prevent the nuclear translocation and transcriptional activity of NF- $\kappa B$ by binding the IkB kinase (IKK)-related kinase IKKE, which is part of the upstream complex involved in activation and subsequent translocation of NF- $\kappa \mathrm{B}$ to the nucleus (Pythoud et al., 2012). Also, infection of monocytes with Kaposi's sarcoma-associated herpesvirus (KHSV) inhibits both TLR2 and TLR4 signaling (Lagos et al., 2008; Meyer et al., 2013). The KHSV replication and transcription activator (RTA) induces the degradation of mRNA encoding MyD88. RTA also promotes proteasomal degradation of TLR3 adaptor protein TRIF, which blocks downstream signaling (Bussey et al., 2014).

Furthermore, Arenavirus NP is involved in the suppression of type I IFN responses through an early interference with the IRF3 activation pathway (Martinez-Sobrido et al., 2007). This leads to inhibition of type I IFN production and ISGs expression, needed for the establishment of an antiviral state. IRF3 is normally present in the cytoplasm in an inactive state. However, in response to viral infection, it is phosphorylated and can either dimerize or form a complex with IRF7 to translocate to the nucleus where it activates the transcription of IFN $\alpha$ and IFN $\beta$. LCMV-NP inhibits IRF3 phosphorylation through the same mechanism as NF- $\mathrm{BB}$ inhibition (Pythoud et al., 2012). The classical IKK complex IKK $\alpha / \operatorname{IKK} \beta$ is involved in activation 
of NF- $\kappa$ B, whereas TBK1 (TANK-binding kinase) and IKK $\varepsilon$ can also activate IRF by direct phosphorylation of IRF3 and IRF7. By binding to IKK $\varepsilon$ and inhibiting its function, LCMVNP inhibits phosphorylation of IRF3, preventing its activation and nuclear translocation (Pythoud et al., 2012). Another viral inhibitory protein, KHSV ORF45 acts as a competitive substrate for IKKE and TBK1 to prevent the activation of IRF7 (Liang et al., 2012). As well, the Ebola virus (EBOV) VP35 blocks TBK1 and IKKE-mediated IRF7 phosphorylation, leading to the inhibition of type I IFN production (Leung et al., 2009; Kimberlin et al., 2010).

Viruses can induce type I IFN production through cytosolic PRRs such as RIG-I and MDA5, which detect viral 5'triphosphorylated ssRNA and dsRNA present in the cytoplasm of infected cells. When activated by viral dsRNA, RIG-I and MDA5 lead to the activation of signaling pathways that activate IRFs, and NF- $\mathrm{B}$, that translocate to the nucleus and activate the transcription of inflammatory cytokines and type I IFNs (Figure 1). Arenavirus-NP evades immune detection by both RIG-I and MDA5, because the C-terminal domain of NP has exonuclease activity and can digest dsRNA, preventing its sensing by RIG-I and MDA5 and subsequent production of type I IFNs (Borrow et al., 2010; Hastie et al., 2011; Reynard et al., 2014; Huang et al., 2015). However, this inhibitory mechanism is not fully efficient and small amounts of type I IFN can still be produced.

Arenavirus $\mathrm{Z}$ protein is a small zinc-binding protein involved in the regulation of replication and transcription of the virus genome, as well as in the mediation of viral budding (Salvato et al., 1992; Perez et al., 2003; Kranzusch and Whelan, 2011). Introducing the $\mathrm{Z}$ protein of pathogenic arenaviruses into nonpathogenic species was shown to enhance viral replication in $M \varphi$, which are the early target of these viruses. Interestingly, it has

\section{REFERENCES}

Aguirre, S., Maestre, A. M., Pagni, S., Patel, J. R., Savage, T., Gutman, D., et al. (2012). DENV inhibits type I IFN production in infected cells by cleaving human STING. PLoS Pathog. 8:e1002934. doi: 10.1371/journal.ppat.100 2934

Alothaimeen, T., Trus, E., Basta, S., and Gee, K. (2021). Differential TLR7-mediated cytokine expression by R848 in M-CSF- versus GM-CSF-derived macrophages after LCMV infection. J. Gen. Virol. 102:001541. doi: 10.1099/jgv.0.001541

Arango Duque, G., and Descoteaux, A. (2014). Macrophage cytokines: involvement in immunity and infectious diseases. Front. Immunol. 5:491. doi: 10.3389/ fimmu.2014.00491

Avdic, S., Cao, J. Z., Mcsharry, B. P., Clancy, L. E., Brown, R., Steain, M., et al. (2013). Human cytomegalovirus interleukin-10 polarizes monocytes toward a deactivated M2c phenotype to repress host immune responses. J. Virol. 87, 10273-10282. doi: 10.1128/JVI.00912-13

Baize, S., Kaplon, J., Faure, C., Pannetier, D., Georges-Courbot, M. C., and Deubel, V. (2004). Lassa virus infection of human dendritic cells and macrophages is productive but fails to activate cells. J. Immunol. 172, 2861-2869. doi: 10.4049/ jimmunol.172.5.2861

Banete, A., Gee, K., and Basta, S. (2021). Sustained IL-4 priming of macrophages enhances the inflammatory response to TLR7/8 ligand R848. J. Leukoc Biol. [Online ahead of print] 1-13. doi: 10.1002/JLB.3A0520-293RR

Banete, A., Seaver, K., Bakshi, D., Gee, K., and Basta, S. (2018). On taking the STING out of immune activation. J. Leukoc Biol. [Online ahead of print] 1189-1195. doi: 10.1002/JLB.2MIR0917-383R been reported that the $\mathrm{Z}$ protein of all arenaviruses pathogenic to humans, including LCMV, is able to inhibit IFN production by binding to RLRs. The $\mathrm{Z}$ protein binds to the N-terminal CARDdomain of RIG-I and MDA5, which disrupts their interaction with MAVS to inhibit downstream signaling (Xing et al., 2015b).

Another well-characterized viral immune inhibitory protein is the EBOV VP35 protein. VP35 prevents the activation of RIG-I signaling by shielding the viral dsRNA from detection by effectively coating the viral genome and preventing its interaction with cytosolic detectors (Leung et al., 2011).

In conclusion, viruses evolved multiple tactics to cope with the host immune response, which taught us many lessons in Microbiology. Activated $\mathrm{M} \varphi$ antiviral functions can be dictated by their polarization and activation signals they exchange. In certain infections, polarization toward one end of the spectrum may be associated with immunopathology. This imbalance can provide an advantage for viral replication. Lessons gathered from the above studies necessitate more research in understanding and utilizing polarized $\mathrm{M} \varphi$ in antiviral immunotherapeutics.

\section{AUTHOR CONTRIBUTIONS}

$\mathrm{AB}, \mathrm{JB}, \mathrm{RW}$, and $\mathrm{SB}$ conceptualized and wrote the review. All authors contributed to the article and approved the submitted version.

\section{FUNDING}

The authors are supported by grants from the Natural Sciences and Engineering Research Council of Canada, and the Ministry of Ontario.

Basta, S., Knoetig, S., Summerfield, A., and Mccullough, K. C. (2001). Lipopolysaccharide and phorbol 12-myristate 13-acetate both impair monocyte differentiation, relating cellular function to virus susceptibility. Immunology 103, 488-497. doi: 10.1046/j.1365-2567.2001.01266.x

Basta, S., Knoetig, S. M., Spagnuolo-Weaver, M., Allan, G., and Mccullough, K. C. (1999). Modulation of monocytic cell activity and virus susceptibility during differentiation into macrophages. J. Immunol. 162, 3961-3969.

Bayer, C., Varani, S., Wang, L., Walther, P., Zhou, S., Straschewski, S., et al. (2013). Human cytomegalovirus infection of M1 and M2 macrophages triggers inflammation and autologous T-cell proliferation. J. Virol. 87, 67-79. doi: 10. 1128/JVI.01585-12

Beadling, C., and Slifka, M. K. (2004). How do viral infections predispose patients to bacterial infections? Curr. Opin. Infect. Dis. 17, 185-191. doi: 10.1097/ 00001432-200406000-00003

Bender, S., Reuter, A., Eberle, F., Einhorn, E., Binder, M., and Bartenschlager, R. (2015). Activation of Type I and III interferon response by mitochondrial and peroxisomal MAVS and inhibition by hepatitis C virus. PLoS Pathog. 11:e1005264. doi: 10.1371/journal.ppat.1005264

Biswas, S. K., and Mantovani, A. (2010). Macrophage plasticity and interaction with lymphocyte subsets: cancer as a paradigm. Nat. Immunol. 11, 889-896. doi: 10.1038/ni.1937

Borrow, P., Martinez-Sobrido, L., and De La Torre, J. C. (2010). Inhibition of the type I interferon antiviral response during arenavirus infection. Viruses 2, 2443-2480. doi: 10.3390/v2112443

Boumaza, A., Gay, L., Mezouar, S., Bestion, E., Diallo, A. B., Michel, M., et al. (2021). Monocytes and macrophages, targets of severe acute 
respiratory syndrome coronavirus 2: the clue for coronavirus disease 2019 immunoparalysis. J. Infect. Dis. 224, 395-406. doi: 10.1093/infdis/jiab044

Brufsky, A. (2020). Hyperglycemia, hydroxychloroquine, and the COVID-19 pandemic. J. Med. Virol. 92, 770-775. doi: 10.1002/jmv.25887

Burdo, T. H., Walker, J., and Williams, K. C. (2015). Macrophage polarization in AIDS: dynamic interface between anti-viral and anti-inflammatory macrophages during acute and chronic infection. J. Clin. Cell Immunol. 6:333.

Bussey, K. A., Reimer, E., Todt, H., Denker, B., Gallo, A., Konrad, A., et al. (2014). The gammaherpesviruses Kaposi's sarcoma-associated herpesvirus and murine gammaherpesvirus 68 modulate the Toll-like receptor-induced proinflammatory cytokine response. J. Virol. 88, 9245-9259. doi: 10.1128/JVI. 00841- 14

Cassol, E., Cassetta, L., Rizzi, C., Alfano, M., and Poli, G. (2009). M1 and M2a polarization of human monocyte-derived macrophages inhibits HIV-1 replication by distinct mechanisms. J. Immunol. 182, 6237-6246. doi: 10.4049/ jimmunol.0803447

Changotra, H., Jia, Y., Moore, T. N., Liu, G., Kahan, S. M., Sosnovtsev, S. V., et al. (2009). Type I and type II interferons inhibit the translation of murine norovirus proteins. J. Virol. 83, 5683-5692. doi: 10.1128/JVI.00231-09

Che Mat, N. F., Siddiqui, S., Mehta, D., Seaver, K., Banete, A., Alothaimeen, T., et al. (2018). Lymphocytic choriomeningitis virus infection of dendritic cells interferes with TLR-induced IL-12/IL-23 cytokine production in an IL-10 independent manner. Cytokine 108, 105-114. doi: 10.1016/j.cyto.2018.03.017

Christensen, M. H., Jensen, S. B., Miettinen, J. J., Luecke, S., Prabakaran, T., Reinert, L. S., et al. (2016). HSV-1 ICP27 targets the TBK1-activated STING signalsome to inhibit virus-induced type I IFN expression. EMBO J. 35, 1385-1399. doi: 10.15252/embj.201593458

Dixit, E., Boulant, S., Zhang, Y., Lee, A. S., Odendall, C., Shum, B., et al. (2010). Peroxisomes are signaling platforms for antiviral innate immunity. Cell 141, 668-681. doi: 10.1016/j.cell.2010.04.018

Gee, K., Guzzo, C., Che Mat, N. F., Ma, W., and Kumar, A. (2009). The IL-12 family of cytokines in infection, inflammation and autoimmune disorders. Inflamm. Allergy Drug Targets 8, 40-52. doi: 10.2174/187152809787582507

Gomez-Villamandos, J. C., Bautista, M. J., Sanchez-Cordon, P. J., and Carrasco, L. (2013). Pathology of African swine fever: the role of monocyte-macrophage. Virus Res. 173, 140-149. doi: 10.1016/j.virusres.2013.01.017

Gordon, S., and Taylor, P. R. (2005). Monocyte and macrophage heterogeneity. Nat. Rev. Immunol. 5, 953-964. doi: 10.1038/nri1733

Gracia-Hernandez, M., Sotomayor, E. M., and Villagra, A. (2020). Targeting macrophages as a therapeutic option in coronavirus disease 2019. Front. Pharmacol. 11:577571. doi: 10.3389/fphar.2020.577571

Grunewald, M. E., Chen, Y., Kuny, C., Maejima, T., Lease, R., Ferraris, D., et al. (2019). The coronavirus macrodomain is required to prevent PARP-mediated inhibition of virus replication and enhancement of IFN expression. PLoS Pathog. 15:e1007756. doi: 10.1371/journal.ppat.1007756

Hastie, K. M., Kimberlin, C. R., Zandonatti, M. A., Macrae, I. J., and Saphire, E. O. (2011). Structure of the Lassa virus nucleoprotein reveals a dsRNA-specific $3^{\prime}$ to $5^{\prime}$ exonuclease activity essential for immune suppression. Proc. Natl. Acad. Sci. U.S.A. 108, 2396-2401. doi: 10.1073/pnas.1016404108

Herbein, G., and Varin, A. (2010). The macrophage in HIV-1 infection: from activation to deactivation? Retrovirology 7:33. doi: 10.1186/1742-4690-7-33

Hou, F., Sun, L., Zheng, H., Skaug, B., Jiang, Q. X., and Chen, Z. J. (2011). MAVS forms functional prion-like aggregates to activate and propagate antiviral innate immune response. Cell 146, 448-461. doi: 10.1016/j.cell.2011.06.041

Hou, W., Jin, Y. H., Kang, H. S., and Kim, B. S. (2014). Interleukin-6 (IL-6) and IL17 synergistically promote viral persistence by inhibiting cellular apoptosis and cytotoxic T cell function. J. Virol. 88, 8479-8489. doi: 10.1128/JVI.00724-14

Huang, Q., Shao, J., Lan, S., Zhou, Y., Xing, J., Dong, C., et al. (2015). In vitro and in vivo characterizations of pichinde viral nucleoprotein exoribonuclease functions. J. Virol. 89, 6595-6607. doi: 10.1128/JVI.00009-15

Ichikawa, T., Nakao, K., Nakata, K., Yamashita, M., Hamasaki, K., Shigeno, M., et al. (2002). Involvement of IL-1beta and IL-10 in IFN-alpha-mediated antiviral gene induction in human hepatoma cells. Biochem. Biophys. Res. Commun. 294, 414-422. doi: 10.1016/S0006-291X(02)00502-8

Iwasaki, A., and Medzhitov, R. (2010). Regulation of adaptive immunity by the innate immune system. Science 327, 291-295.

Iwata, H., Goettsch, C., Sharma, A., Ricchiuto, P., Goh, W. W., Halu, A., et al. (2016). PARP9 and PARP14 cross-regulate macrophage activation via STAT1 ADP-ribosylation. Nat. Commun. 7:12849. doi: 10.1038/ncomms12849
Jangra, S., Bharti, A., Lui, W. Y., Chaudhary, V., Botelho, M. G., Yuen, K. S., et al. (2021). Suppression of JAK-STAT signaling by Epstein-Barr virus tegument protein BGLF2 through recruitment of SHP1 phosphatase and promotion of STAT2 degradation. J. Virol. 95:e0102721. doi: 10.1128/JVI.01027-21

Jarasch, N., Martin, U., Kamphausen, E., Zell, R., Wutzler, P., and Henke, A. (2005). Interferon-gamma-induced activation of nitric oxide-mediated antiviral activity of macrophages caused by a recombinant coxsackievirus B3. Viral Immunol. 18, 355-364. doi: 10.1089/vim.2005.18.355

Jenkins, C., Abendroth, A., and Slobedman, B. (2004). A novel viral transcript with homology to human interleukin-10 is expressed during latent human cytomegalovirus infection. J. Virol. 78, 1440-1447. doi: 10.1128/jvi.78.3.14401447.2004

Kadowaki, N., and Liu, Y. J. (2002). Natural type I interferon-producing cells as a link between innate and adaptive immunity. Hum. Immunol. 63, 1126-1132. doi: 10.1016/s0198-8859(02)00751-6

Kawai, T., and Akira, S. (2009). The roles of TLRs, RLRs and NLRs in pathogen recognition. Int. Immunol. 21, 317-337. doi: 10.1093/intimm/dxp017

Keppler, S. J., Rosenits, K., Koegl, T., Vucikuja, S., and Aichele, P. (2012). Signal 3 cytokines as modulators of primary immune responses during infections: the interplay of type I IFN and IL-12 in CD8 T cell responses. PLoS One 7:e40865. doi: 10.1371/journal.pone.0040865

Kimberlin, C. R., Bornholdt, Z. A., Li, S., Woods, V. L. Jr., Macrae, I. J., and Saphire, E. O. (2010). Ebolavirus VP35 uses a bimodal strategy to bind dsRNA for innate immune suppression. Proc. Natl. Acad. Sci. U.S.A. 107, 314-319. doi: 10.1073/pnas.0910547107

Kotenko, S. V., Saccani, S., Izotova, L. S., Mirochnitchenko, O. V., and Pestka, S. (2000). Human cytomegalovirus harbors its own unique IL-10 homolog (cmvIL-10). Proc. Natl. Acad. Sci. U.S.A. 97, 1695-1700. doi: 10.1073/pnas.97.4. 1695

Kranzusch, P. J., and Whelan, S. P. (2011). Arenavirus Z protein controls viral RNA synthesis by locking a polymerase-promoter complex. Proc. Natl. Acad. Sci. U.S.A. 108, 19743-19748. doi: 10.1073/pnas.1112742108

Lagos, D., Vart, R. J., Gratrix, F., Westrop, S. J., Emuss, V., Wong, P. P., et al. (2008). Toll-like receptor 4 mediates innate immunity to Kaposi sarcoma herpesvirus. Cell Host Microbe 4, 470-483. doi: 10.1016/j.chom.2008.09.012

Lawrence, T., and Natoli, G. (2011). Transcriptional regulation of macrophage polarization: enabling diversity with identity. Nat. Rev. Immunol. 11, 750-761. doi: $10.1038 /$ nri3088

Lee, D. H., and Ghiasi, H. (2017). Roles of M1 and M2 macrophages in herpes simplex virus 1 infectivity. J. Virol. 91, e578-e517. doi: 10.1128/JVI.00578-17

Leung, D. W., Ginder, N. D., Fulton, D. B., Nix, J., Basler, C. F., Honzatko, R. B., et al. (2009). Structure of the Ebola VP35 interferon inhibitory domain. Proc. Natl. Acad. Sci. U.S.A. 106, 411-416.

Leung, L. W., Park, M. S., Martinez, O., Valmas, C., Lopez, C. B., and Basler, C. F. (2011). Ebolavirus VP35 suppresses IFN production from conventional but not plasmacytoid dendritic cells. Immunol. Cell Biol. 89, 792-802. doi: 10.1038/icb.2010.169

Li, K., Xu, W., Guo, Q., Jiang, Z., Wang, P., Yue, Y., et al. (2009). Differential macrophage polarization in male and female $B A L B / c$ mice infected with coxsackievirus B3 defines susceptibility to viral myocarditis. Circ. Res. 105, 353-364. doi: 10.1161/CIRCRESAHA.109.195230

Li, Q., Lin, L., Tong, Y., Liu, Y., Mou, J., Wang, X., et al. (2018). TRIM29 negatively controls antiviral immune response through targeting STING for degradation. Cell Discov. 4:13.

Liang, Q., Fu, B., Wu, F., Li, X., Yuan, Y., and Zhu, F. (2012). ORF45 of Kaposi's sarcoma-associated herpesvirus inhibits phosphorylation of interferon regulatory factor 7 by IKKepsilon and TBK1 as an alternative substrate. J. Virol. 86, 10162-10172. doi: 10.1128/JVI.05224-11

Lucin, P., Jonjic, S., Messerle, M., Polic, B., Hengel, H., and Koszinowski, U. H. (1994). Late phase inhibition of murine cytomegalovirus replication by synergistic action of interferon-gamma and tumour necrosis factor. J. Gen. Virol. 75(Pt 1), 101-110. doi: 10.1099/0022-1317-75-1-101

Mantovani, A., Sica, A., Sozzani, S., Allavena, P., Vecchi, A., and Locati, M. (2004). The chemokine system in diverse forms of macrophage activation and polarization. Trends Immunol. 25, 677-686. doi: 10.1016/j.it.2004.09.015

Mariani, M. K., Dasmeh, P., Fortin, A., Caron, E., Kalamujic, M., Harrison, A. N., et al. (2019). The combination of IFN beta and TNF induces an antiviral and immunoregulatory program via non-canonical pathways involving STAT2 and IRF9. Cells 8:919. doi: 10.3390/cells8080919 
Martinez, F. O., Gordon, S., Locati, M., and Mantovani, A. (2006). Transcriptional profiling of the human monocyte-to-macrophage differentiation and polarization: new molecules and patterns of gene expression. J. Immunol. 177, 7303-7311. doi: 10.4049/jimmunol.177.10.7303

Martinez-Sobrido, L., Giannakas, P., Cubitt, B., Garcia-Sastre, A., and De La Torre, J. C. (2007). Differential inhibition of type I interferon induction by arenavirus nucleoproteins. J. Virol. 81, 12696-12703. doi: 10.1128/JVI.00882-07

McCullough, K. C., Basta, S., Knotig, S., Gerber, H., Schaffner, R., Kim, Y. B., et al. (1999). Intermediate stages in monocyte-macrophage differentiation modulate phenotype and susceptibility to virus infection. Immunology 98, 203-212. doi: 10.1046/j.1365-2567.1999.00867.x

Mehrotra, P., Riley, J. P., Patel, R., Li, F., Voss, L., and Goenka, S. (2011). PARP-14 functions as a transcriptional switch for Stat6-dependent gene activation. J. Biol. Chem. 286, 1767-1776. doi: 10.1074/jbc.M110.157768

Mehta, D., Petes, C., Gee, K., and Basta, S. (2015). The role of virus infection in deregulating the cytokine response to secondary bacterial infection. J. Interferon Cytokine Res. 35, 925-934. doi: 10.1089/jir.2015.0072

Meyer, F., Ehlers, E., Steadman, A., Waterbury, T., Cao, M., and Zhang, L. (2013). TLR-TRIF pathway enhances the expression of KSHV replication and transcription activator. J. Biol. Chem. 288, 20435-20442. doi: 10.1074/jbc.M113. 487421

Morales-Nebreda, L., Misharin, A. V., Perlman, H., and Budinger, G. R. (2015). The heterogeneity of lung macrophages in the susceptibility to disease. Eur. Respir. Rev. 24, 505-509. doi: 10.1183/16000617.0031-2015

Mulder, R., Banete, A., Seaver, K., and Basta, S. (2017). M(IL-4) tissue macrophages support efficient interferon-gamma production in antigen-specific CD8(+) $\mathrm{T}$ cells with reduced proliferative capacity. Front. Immunol. 8:1629. doi: 10.3389/ fimmu.2017.01629

Murray, P. J., Allen, J. E., Biswas, S. K., Fisher, E. A., Gilroy, D. W., Goerdt, S., et al. (2014). Macrophage activation and polarization: nomenclature and experimental guidelines. Immunity 41, 14-20. doi: 10.1016/j.immuni.2014.0 6.008

Naito, M., Umeda, S., Yamamoto, T., Moriyama, H., Umezu, H., Hasegawa, G., et al. (1996). Development, differentiation, and phenotypic heterogeneity of murine tissue macrophages. J. Leukoc Biol. 59, 133-138. doi: 10.1002/jlb.59.2.133

Nathan, C. F., and Hibbs, J. B. Jr. (1991). Role of nitric oxide synthesis in macrophage antimicrobial activity. Curr. Opin. Immunol. 3, 65-70. doi: 10. 1016/0952-7915(91)90079-g

Nathan, C. F., Murray, H. W., Wiebe, M. E., and Rubin, B. Y. (1983). Identification of interferon-gamma as the lymphokine that activates human macrophage oxidative metabolism and antimicrobial activity. J. Exp. Med. 158, 670-689. doi: 10.1084/jem.158.3.670

Nikitina, E., Larionova, I., Choinzonov, E., and Kzhyshkowska, J. (2018). Monocytes and macrophages as viral targets and reservoirs. Int. J. Mol. Sci. 19:2821. doi: 10.3390/ijms19092821

Odendall, C., Dixit, E., Stavru, F., Bierne, H., Franz, K. M., Durbin, A. F., et al. (2014). Diverse intracellular pathogens activate type III interferon expression from peroxisomes. Nat. Immunol. 15, 717-726. doi: 10.1038/ni.2915

O'Neill, L. A. (2008). The interleukin-1 receptor/Toll-like receptor superfamily: 10 years of progress. Immunol. Rev. 226, 10-18. doi: 10.1111/j.1600-065X.2008. 00701.x

Paulina Achita, A. B. (2015). Immortalized murine macrophage cell line as a model for macrophage polarization into classically activated M(IFN $\gamma+\mathrm{LPS})$ or alternatively activated M(IL-4) macrophages. J. Clin. Cellular Immunol. 6, 1-7.

Perez, M., Craven, R. C., and De La Torre, J. C. (2003). The small RING finger protein $\mathrm{Z}$ drives arenavirus budding: implications for antiviral strategies. Proc. Natl. Acad. Sci. U.S.A. 100, 12978-12983. doi: 10.1073/pnas.213378 2100

Petes, C., Wynick, C., Guzzo, C., Mehta, D., Logan, S., Banfield, B. W., et al. (2017). IL-27 enhances LPS-induced IL-1beta in human monocytes and murine macrophages. J. Leukoc Biol. 102, 83-94. doi: 10.1189/jlb.3A0316-098R

Petrina, M., Martin, J., and Basta, S. (2021). Granulocyte macrophage colonystimulating factor has come of age: from a vaccine adjuvant to antiviral immunotherapy. Cytokine Growth Factor Rev. 59, 101-110. doi: 10.1016/j. cytogfr.2021.01.001

Pythoud, C., Rodrigo, W., Pasqual, G., Rothenberger, S., Martínez-Sobrido, L., De La Torre, J. C., et al. (2012). Arenavirus nucleoprotein targets interferon regulatory factor-activating kinase IKKE. J. Virol. 86, 7728-7738. doi: 10.1128/ JVI.00187-12

Reikine, S., Nguyen, J. B., and Modis, Y. (2014). Pattern recognition and signaling mechanisms of RIG-I and MDA5. Front. Immunol. 5:342. doi: 10.3389/fimmu. 2014.00342

Reynard, S., Russier, M., Fizet, A., Carnec, X., and Baize, S. (2014). Exonuclease domain of the Lassa virus nucleoprotein is critical to avoid RIG-I signaling and to inhibit the innate immune response. J. Virol. 88, 13923-13927. doi: 10.1128/JVI.01923-14

Rodrigo, W. W., Ortiz-Riano, E., Pythoud, C., Kunz, S., De La Torre, J. C., and Martinez-Sobrido, L. (2012). Arenavirus nucleoproteins prevent activation of nuclear factor kappa B. J. Virol. 86, 8185-8197. doi: 10.1128/JVI. 07240- 11

Russo, L. C., Tomasin, R., Matos, I. A., Manucci, A. C., Sowa, S. T., Dale, K., et al. (2021). The SARS-CoV-2 Nsp3 macrodomain reverses PARP9/DTX3Ldependent ADP-ribosylation induced by interferon signaling. J. Biol. Chem. 297:101041. doi: 10.1016/j.jbc.2021.101041

Ruytinx, P., Proost, P., Van Damme, J., and Struyf, S. (2018). Chemokine-induced macrophage polarization in inflammatory conditions. Front. Immunol. 9:1930. doi: 10.3389/fimmu.2018.01930

Salvato, M. S., Schweighofer, K. J., Burns, J., and Shimomaye, E. M. (1992). Biochemical and immunological evidence that the $11 \mathrm{kDa}$ zinc-binding protein of lymphocytic choriomeningitis virus is a structural component of the virus. Virus Res. 22, 185-198. doi: 10.1016/0168-1702(92)90050-j

Sang, Y., Miller, L. C., and Blecha, F. (2015). Macrophage polarization in virus-host interactions. J. Clin. Cell Immunol. 6:311. doi: 10.4172/2155-9899. 1000311

Sica, A., Erreni, M., Allavena, P., and Porta, C. (2015). Macrophage polarization in pathology. Cell Mol. Life Sci. 72, 4111-4126. doi: 10.1007/s00018-0151995-y

Sica, A., and Mantovani, A. (2012). Macrophage plasticity and polarization: in vivo veritas. J. Clin. Invest. 122, 787-795. doi: 10.1172/JCI59643

Smale, S. T. (2010). Selective transcription in response to an inflammatory stimulus. Cell 140, 833-844. doi: 10.1016/j.cell.2010.01.037

Stein, M., Keshav, S., Harris, N., and Gordon, S. (1992). Interleukin 4 potently enhances murine macrophage mannose receptor activity: a marker of alternative immunologic macrophage activation. J. Exp. Med. 176, 287-292. doi: $10.1084 /$ jem.176.1.287

Sun, L., Wu, J., Du, F., Chen, X., and Chen, Z. J. (2013). Cyclic GMP-AMP synthase is a cytosolic DNA sensor that activates the type I interferon pathway. Science 339, 786-791. doi: 10.1126/science. 1232458

Takahashi, K., Naito, M., and Takeya, M. (1996). Development and heterogeneity of macrophages and their related cells through their differentiation pathways. Pathol. Int. 46, 473-485. doi: 10.1111/j.1440-1827.1996.tb03641.x

Takeuchi, O., and Akira, S. (2010). Pattern recognition receptors and inflammation. Cell 140, 805-820. doi: 10.1016/j.cell.2010.01.022

Tanaka, T., Narazaki, M., and Kishimoto, T. (2014). IL-6 in inflammation, immunity, and disease. Cold Spring Harb. Perspect. Biol. 6:a016295. doi: 10. 1101/cshperspect.a016295

Taylor, G. S., Long, H. M., Brooks, J. M., Rickinson, A. B., and Hislop, A. D. (2015). The immunology of Epstein-Barr virus-induced disease. Annu. Rev. Immunol. 33, 787-821. doi: 10.1146/annurev-immunol-032414-112326

Trivedi, N. H., Yu, J. J., Hung, C. Y., Doelger, R. P., Navara, C. S., Armitige, L. Y., et al. (2018). Microbial co-infection alters macrophage polarization, phagosomal escape, and microbial killing. Innate Immun. 24, 152-162. doi: $10.1177 / 1753425918760180$

Trus, E., Basta, S., and Gee, K. (2020). Who's in charge here? Macrophage colony stimulating factor and granulocyte macrophage colony stimulating factor: competing factors in macrophage polarization. Cytokine 127:154939. doi: 10 . 1016/j.cyto.2019.154939

Tugal, D., Liao, X., and Jain, M. K. (2013). Transcriptional control of macrophage polarization. Arterioscler Thromb Vasc. Biol. 33, 1135-1144. doi: 10.1161/ ATVBAHA.113.301453

Vazquez, C., and Horner, S. M. (2015). MAVS coordination of antiviral innate immunity. J. Virol. 89, 6974-6977. doi: 10.1128/JVI.01918-14

Xing, J., Chai, Z., Ly, H., and Liang, Y. (2015a). Differential inhibition of macrophage activation by lymphocytic choriomeningitis virus and pichinde 
virus is mediated by the Z Protein N-Terminal domain. J. Virol. 89, 1251312517. doi: 10.1128/JVI.01674- 15

Xing, J., Ly, H., and Liang, Y. (2015b). The $\mathrm{Z}$ proteins of pathogenic but not nonpathogenic arenaviruses inhibit RIG-I-like receptor-dependent interferon production. J. Virol. 89, 2944-2955.

Xing, J., Zhang, A., Du, Y., Fang, M., Minze, L. J., Liu, Y. J., et al. (2021). Identification of poly(ADP-ribose) polymerase 9 (PARP9) as a noncanonical sensor for RNA virus in dendritic cells. Nat. Commun. 12:2681. doi: 10.1038/ s41467-021-23003-4

Xing, J., Zhang, A., Minze, L. J., Li, X. C., and Zhang, Z. (2018). TRIM29 negatively regulates the Type I IFN production in response to RNA virus. J. Immunol. 201, 183-192. doi: 10.4049/jimmunol.1701569

Xing, J., Zhang, A., Zhang, H., Wang, J., Li, X. C., Zeng, M. S., et al. (2017). TRIM29 promotes DNA virus infections by inhibiting innate immune response. Nat. Commun. 8:945. doi: 10.1038/s41467-017-00101-w

Yunna, C., Mengru, H., Lei, W., and Weidong, C. (2020). Macrophage M1/M2 polarization. Eur. J. Pharmacol. 877:173090.

Zhang, W., Zhang, Y., He, Y., Wang, X., and Fang, Q. (2019). Lipopolysaccharide mediates time-dependent macrophage M1/M2 polarization through the Tim3/Galectin-9 signalling pathway. Exp. Cell Res. 376, 124-132. doi: 10.1016/j. yexcr.2019.02.007

Zhang, Y., Mao, D., Roswit, W. T., Jin, X., Patel, A. C., Patel, D. A., et al. (2015). PARP9-DTX3L ubiquitin ligase targets host histone $\mathrm{H} 2 \mathrm{BJ}$ and viral 3C protease to enhance interferon signaling and control viral infection. Nat. Immunol. 16, 1215-1227. doi: 10.1038/ni.3279

Zheng, M., Karki, R., Williams, E. P., Yang, D., Fitzpatrick, E., Vogel, P., et al. (2021). TLR2 senses the SARS-CoV-2 envelope protein to produce inflammatory cytokines. Nat. Immunol. 22, 829-838. doi: 10.1038/s41590-02100937-x

Conflict of Interest: The authors declare that the research was conducted in the absence of any commercial or financial relationships that could be construed as a potential conflict of interest.

Publisher's Note: All claims expressed in this article are solely those of the authors and do not necessarily represent those of their affiliated organizations, or those of the publisher, the editors and the reviewers. Any product that may be evaluated in this article, or claim that may be made by its manufacturer, is not guaranteed or endorsed by the publisher.

Copyright (c) 2022 Banete, Barilo, Whittaker and Basta. This is an open-access article distributed under the terms of the Creative Commons Attribution License (CC BY). The use, distribution or reproduction in other forums is permitted, provided the original author(s) and the copyright owner(s) are credited and that the original publication in this journal is cited, in accordance with accepted academic practice. No use, distribution or reproduction is permitted which does not comply with these terms. 